\title{
Los médicos chilenos en la época del Holocausto
}

Chilean doctors in the Holocaust era

Dr. Moshe Nes El nesel@netvision.net.il Tel Aviv, Israel

\section{Resumen}

Como su nombre lo indica, el artículo trata de médicos chilenos, que estudiaron en Alemania, en la época del Holocausto. El autor se preocupa de contextualizar la época y mencionar algunos nombres considerados importantes en la historia de la medicina nacional.

Palabras clave: Holocausto, Chile, médicos chilenos.

\begin{abstract}
The article is related to Chilean physicians who studied in Germany in the Holocaust era. The author is concerned to contextualize the time and he mentions a few names considered important in the history of national medicine
\end{abstract}

Keywords: Holocaust, Chile, chilean physicians.

\section{Antecedentes}

Desde la más temprana edad de la colonización española en el territorio chileno tenemos noticias de familias alemanas que se establecieron en Chile entroncándose con las más altas aristocracias del país. En los decenios del 30 y del 40 del siglo XIX comienza una colonización alemana en la zona de Valdivia y de la zona araucana. Los colonos alemanes mantuvieron su religión y cultura, pero también se integraron en la vida del país contribuyendo al progreso de la zona. ${ }^{1}$

\footnotetext{
${ }^{1}$ Butland.G.J. "The human geography of southern Chile". Vicente Pérez Rosales - "Recuerdos del pasado".
} 
Las relaciones entre Chile y Alemania fueron durante el siglo XIX muy estrechas. Durante la Guerra del Pacífico (1879-1882) las potencias europeas y los países limítrofes con Chile lamentaron el triunfo de Chile en la guerra contra Perú y Bolivia y la anexión de ese país de vastos territorios que habían pertenecido a Perú y Bolivia. La conquista de Chile de esos territorios provocaba fuertes pérdidas a intereses europeos y norteamericanos que intentaron presionar a Chile para lograr que regresara a los límites anteriores y que se pagaran gruesas indemnizaciones a los nacionales de esos países que vivían en la zona y que habían sufrido pérdidas en la guerra. El único país europeo que defendió a Chile contra esas exigencias fue el Imperio Alemán. Esa actitud de Alemania influenció en un mayor acercamiento entre los dos países, Chile abrió una delegación en Berlín y comenzaron a contratarse profesores secundarios que durante un largo período fueron los propulsores de la educación en Chile. ${ }^{2}$ Hasta 1870 Chile orientó la formación de su ejército imitando al ejército francés, pero después de la derrota de Francia en Sedan en 1971 y el triunfo de Alemania, Chile cambió de orientación y desde ese momento hasta muy entrado el siglo $\mathrm{XX}$, el ejército chileno fue dirigido y organizado por oficiales alemanes contratados ó por oficiales chilenos que tuvieron largos períodos de instrucción en Alemania. La influencia de la instrucción militar alemana hizo que en varios lugares se llamara a Chile la Prusia de la América latina.

Después de la Primera Guerra Mundial, Alemania y Chile sufrieron profundas crisis sociales y económicas que iban a agravarse con la crisis mundial de 1929, Alemania, que había sido castigada por las naciones triunfantes en la Primera Guerra Mundial tuvo que pagar una cuantiosa indemnización de guerra, a la que se agregaron los gastos que tuvo Alemania después de esa conflagración para normalizar la situación del país. La situación económica de Alemania provocó una gran crisis política y social, se crearon poderosos movimientos comunistas y se desataron huelgas y otras actividades de esos sectores. También se organizó una derecha militante y reaccionaria que llevó en 1933 al triunfo en las elecciones del partido nazi y la ascensión de Hitler al poder.

Paralelamente a esa situación, en Chile durante esos años hubo una situación económicosocial parecida. Después de la Primera Guerra Mundial hubo una crisis en la venta del salitre, principal producto de importación de Chile, debido a que los alemanes durante la guerra,

\footnotetext{
${ }^{2}$ Labarca A. "Historia de la educación en Chile"
} 
inventaron un salitre sintético, el que ganó los mercados europeos y mundiales y provocó una baja considerable de las exportaciones chilenas. ${ }^{3}$ Esto hizo cerrar numerosos establecimientos salitreros con la consiguiente desocupación de obreros y empleados aumentándose así la agitación social que ya existía en el país años antes, agitación que se amplió con otros problemas económicos como ser el descenso de la actividad económica del Puerto de Valparaíso afectado por la creación del Canal de Panamá que acortaba el viaje entre Europa y el Lejano Oriente.

Esta situación y otras que la acompañaron provocaron huelgas, rebeliones y matanzas y por eso comenzaron también a organizarse los elementos que deseaban traer al país una tranquilidad social y un régimen autocrático, entre estos grupos se encuentra la creación en 1932 del Movimiento Nacional Socialista de Chile.

\section{La emergencia del Movimiento Nacional Socialista en Chile}

El desorden y la anarquía en Chile era parecida a la situación en Europa, donde luego de la anarquía producida al final de la Primera Guerra Mundial, surgieron regímenes mundiales y dictatoriales. En Chile se alzaron en la opinión pública del país, voces que pedían seguir el ejemplo europeo.

En 1923, el prestigioso diario "El Mercurio", publicó una editorial, donde se sugiere que Chile siga el ejemplo de los regímenes totalitarios. Otro prestigioso diario, "Las Ultimas Noticias", publicó también una editorial semejante. Esas editoriales elogiaban el triunfo de Musolini en Italia.

\begin{tabular}{|l|l|l|}
\hline${ }^{3}$ Comercio exterior chileno (1929- 1932$)$ & Exportaciones \\
\hline Año & Importaciones & 276.623 .000 \\
\hline 1929 & 195.078 .000 & 160.437 .000 \\
\hline 1930 & 169.135 .000 & 99.546 .000 \\
\hline 1931 & 85.202 .000 & 35.353 .000 \\
\hline 1932 & 26.018 .000 & \\
\hline
\end{tabular}

Extractado de la Fundación de Investigaciones Históricas, Económicas y Sociales, Edición preparada por Ignacio Ich y Mario Rapoport. 
Los fundadores del Movimiento Nacional socialista en Chile, fueron intelectuales que habían estudiado en Alemania, como el economista Carlos Keller y el abogado González Von Marées, militares que habían desempeñado misiones en Alemania o Italia, como el general Francisco J. Díaz.

La ideología del nuevo movimiento se asemejaba más a los regímenes fascistas, y su nombre era el que usaba el partido nazi en Alemania.

Su ideología sostenía que la solución de los problemas en Chile, era la creación de un estado centralizado, bajo un liderazgo que diera tranquilidad al país y que organizara un régimen armónico de trabajo.

La filosofía de ese partido correspondía a la de Nicolás Palacios, en su libro "Raza Chilena", que sostenía que en Chile se había originado una nueva raza, producto del desarrollo del país. Siendo Chile una de las colonias más pobres de España, llegaron españoles, en general guerreros, que buscaban glorificarse en las campañas contra los indios araucanos. Por su parte, los araucanos demostraron tener un gran valor, y pese a los esfuerzos, los españoles fracasaron en intentar dominarlos. Ese largo contacto provocó el mestizaje entre el guerrero español y la mujer araucana, con la potencialidad para desarrollar una raza especial, la raza chilena, que el Movimiento Nacional Socialista quería promover.

El movimiento chileno adoptó escribir la palabra nazi como naci, para diferenciarse del partido nazi alemán, este planteamiento dio pie a la creación de otro partido nazista organizado por los alemanes residentes en Chile, y que aceptaban las premisas que llegaban desde Alemania. Su jefe era Rudolph Schwartzenberg. En 1935 el Movimiento Nacional Socialista de Chile expulsó el elemento alemán.

Interesante es consignar la posición de los nacis chilenos en relación a los judíos. Podemos resaltar dos épocas, la anterior a 1940, y la posterior hasta la extinción del movimiento. En la primera fase del partido declara que solo se opone a los judíos que no se asimilen al país, pero acepta a aquellos que se integran totalmente al mismo. En el periódico "Trabajo", órgano de partido, se informa el caso de los judíos miembros del partido, y de aquellos que se les considera como chilenos dignos de ser miembros del movimiento. El líder del partido naci 
González Von Marées declaró en una entrevista a un periódico judío-norteamericano, que él era descendiente de una abuela judía. Esa declaración provocó reacciones en su propio partido, lo que tuvo que corregir declarando que su bisabuela era judía, y no su abuela, y de esa forma podía incluirse en la raza aria según las leyes de Nuremberg.

La segunda parte fue influenciada por los triunfos del nazismo, y el problema de los refugiados judíos que llegaron a Chile entre 1937 y 1940. En ese período el Movimiento Nacional Socialista, adoptó una posición más antisemita.

El movimiento naci en Chile creció rápidamente. En las elecciones de 1932, obtuvo 961 votos, y en las de 1937, 14.564. Ese año fueron electos los tres primeros parlamentarios del movimiento, teniendo así una representación en el Parlamento. ${ }^{4}$

\section{Las relaciones entre Alemania y Chile con la subida del nazismo}

En este trabajo trataremos de dar un panorama sobre el impacto de los sucesos de la Alemania Nazista entre el conglomerado de doctores chilenos tanto judíos como no judíos y las proyecciones que tuvieron sus opiniones sobre esa época.

Como ya lo hemos escrito, las relaciones entre los dos países principalmente en lo que se refiere al ejército y a la medicina eran muy estrechas. Tenemos testimonios de altos oficiales chilenos que estudiaron en Alemania distintas disciplinas militares ${ }^{5}$. En cuanto a los estudios médicos, el contacto entre los dos países se realizó ya avanzado el siglo XIX, muchos hijos de inmigrantes alemanes se trasladaron a ese país para estudiar medicina debido al alto nivel que tenía en ese tiempo, y además los jóvenes inmigrantes conocían el alemán muchas veces mejor que el castellano. El primer descendiente de alemanes que fue electo al Parlamento Chileno fue el doctor Emilio Koerner, médico egresado de las universidades alemanas que también desempeñó su profesión.

\footnotetext{
${ }^{4}$ Cuadernos. Centro de estudios judaicos- Universidad de Chile- Diciembre de 2012.

${ }^{5}$ Dr. Moshe Nes-El, "Memorias del Embajador chileno en Alemania“, Tobías Barros Ortíz, durante la epoca de la Segunda Guerra Mundial y el Holocausto, en Judaica Latinoamericana, Volumen IV Amilat- Jerusalén.
} 
Como en toda nación libre las opiniones entre los facultativos estaban divididas, un importante número de los médicos simpatizaban con el régimen nazi o habían sido becados por Alemania para perfeccionarse en los hospitales de dicha nación. La medicina en Alemania tenía un reconocido renombre antes de la subida de Hitler al poder y de las leyes de Nuremberg. En los primeros años del régimen nazi continuaron siendo un foco de atracción para el perfeccionamiento de médicos.

Veremos cuál fue la influencia alemana para las simpatías frente al régimen nazi cuando los médicos becados volvieron a Chile alarmados por la prepotencia nazi.

El régimen nazi intentó aprovecharse de las condiciones favorables que había en Chile para la propagación de las ideas nazistas, existía en Chile una numerosa colectividad residente de alemanes que tenían su propia red escolar y donde se realizaban actividades sociales y deportivas. Los nazistas lograron rápidamente controlarla y la transformaron en una fuente de difusión de sus ideas, muchos de esos alumnos continuaron posteriormente estudiando entre otras materias, la medicina, y se transformaron en activos agentes de propulsión de los intereses del gobierno alemán.

En momento de crearse el régimen nazi, se fundaron instituciones con el objeto de incrementar la influencia alemana en el país. El Partido Nazi formó una sección para trabajar con los alemanes exiliados en otros países cuyas siglas eran NSDAP.

También los funcionarios diplomáticos alemanes colaboraban activamente buscando médicos que pudieran ser imbuidos en la ideología racista.

Varias instituciones alemanas captaban a los visitantes y estudiantes chilenos y latinoamericanos que iban a estudiar a Alemania e intentaban usarlos para difundir la ideología nazi, los principales eran: el Instituto Emperador Guillermo, la Academia Médica Iberoamericana, etc.

Uno de los propósitos más importantes de la actividad proselitista nazi en Chile fue la de intentar acercar a los médicos chilenos a aceptar la teoría racista del Tercer Reich.

El objetivo de la enseñanza médica nazista tenía como ideal inculcar la teoría racial central en la ideología nazi. El esfuerzo nazi se concentró en el NSDAP. 
La organización nazi se preocupó de que los estudios de sus becados latinoamericanos fueran recepcionados con la mayor comodidad con el objeto no solo de inculcar la ideología nazista sino también la admiración por la Alemania Nazi.

Dentro del marco del Instituto Iberoamericano se creó una academia especial para médicos latinoamericanos, que fue fundada el 9 de abril de 1935.

Uno de los propósitos del plan nazi era la posibilidad de tener un contacto con médicos que hubiesen realizado sus estudios en Alemania y que desearan continuar colaborando con la ideología nazi ${ }^{6}$. En 1938 la academia tenía más de quinientos médicos latinoamericanos como asociados, los que tenían un alto nivel profesional. Los médicos, por lo general, pagaban ellos mismos los costos del viaje al Reich.

Estos contactos continuaron a partir del inicio de la Guerra Mundial, mediante la organización de conferencias científicas con la ayuda de la Radio de Onda Corta Alemana (Deutscher Kurzwellensender) y la publicación de trabajos de investigación alemanes en revistas iberoamericanas especializadas.

La Academia Médica Germano Iberoamericana disponía desde 1939 de todo un programa de radio propio, en castellano y portugués, sobre temas médicos, y que era periódicamente transmitido a América latina, España y Portugal.

El radical cambio ideológico de la Revista médica Germano-Iberoamericana en 1933 corresponde al proceso generalizado de las instituciones científicas alemanas después de la toma hitleriana del poder, la "auto puesta en vereda", y merece ser descrito aquí, porque la estructura y la temática científica y política de esta revista pone de manifiesto las opciones representadas por la Academia Médica Germano Iberoamericana a la que vincularon tantos médicos latinoamericanos y entre ellos, chilenos. Desde 1934 la revista comienza a tener un claro tinte ideológico nazi en los trabajos que publica. Los artículos publicados posteriormente hacen énfasis a la ideología racista y a la eugenesia.

\footnotetext{
${ }^{6}$ Víctor Farías “Los alemanes en Chile Volumen I y II.pag. 105 a 121.
} 
La orientación principal se focalizaba en relación a la selección racial familiar basada "en el principio proveedor del estado y en una política de población apoyada en la autodefensa intrafamiliar". La dirección política del Reich, el NSDAP y sus diferentes instancias, las organizaciones médicas alemanas y sus integrantes militantes sabían entonces claramente lo que debían hacer para obtener el mayor número posible de "multiplicadores" entre los médicos chilenos y latinoamericanos.

Es importante saber si los médicos chilenos, prestigiosos facultativos en su país, podían realmente ignorar lo que, ya desde 1933, estaba sucediendo en Alemania y muy especialmente con sus colegas, en los hospitales y clínicas, en las facultades de medicina de las universidades y en la administración pública cuando estos eran judíos o simplemente opositores consecuentes al régimen nazi fascista.

Los médicos chilenos, por lo menos, no podían ignorarlo porque su más prestigiosa escritora, Gabriela Mistral, lo había advertido masivamente desde las páginas del periódico más difundido en Chile. "El Mercurio", el 16 de junio de 1935, en su artículo "Recados sobre los judíos" y tres años después, en 1938, la Alianza de Intelectuales de Chile, por voz de su presidente Pablo Neruda, iba a pedir a los médicos chilenos que se abstuvieran de viajar a Alemania.

El número de facultativos chilenos que continuó colaborando con las instituciones nazis alemanas fue creciendo gradualmente a pesar de lo que ya se conocía sobre las barbaridades de ese régimen. Si bien es cierto que la mayor parte de los médicos que viajaron al Reich lo hizo pagando al menos sus costos de viaje, en varios casos la gestión se llevó a cabo por iniciativa ministerial (es el caso entre otros del profesor Dr. Alfonso Asenjo, por mediación del ministro, también médico, Eduardo Cruz-Coke, bajo el gobierno del presidente Arturo Alessandri Palma).

Cabe por tanto, analizar la situación a la que se vio enfrentada, en conciencia, la elite de los médicos chilenos que se integró a la institución creada por el Reich, la indesmentible situación de la vida médica en la Alemania de 1935 a 1943, año que termina la colaboración al romper Chile, en lo político, sus relaciones con la Alemania nazi. En un periódico alemán 
aparece un artículo de fuerte tinte antisemita destinado a combatir a los médicos judíos (10 de diciembre de 1932).

El ataque a los médicos judíos y posteriormente su expulsión de los cargos que mantenían, creó una situación de necesidad de abandonar Alemania para buscar nuevos horizontes en otros países. También en la prensa del partido naci-chileno "Trabajo" se publica en agosto de 1933 un artículo alertando sobre la inmigración de dentistas y médicos judíos a Chile.

Todas las estructuras organizativas y los contenidos de estudio en las universidades y clínicas fueron reorganizadas de acuerdo con los principios hitlerianos, abarcando catedráticos, médicos en general, comadronas, enfermeras y todo el personal del hospital, dando a las clínicas y hospitales un aspecto y funcionamiento característicos e inconfundibles.

La terrible situación que se presentó en Alemania con la política nazi y entre otros en lo que afectaba a los médicos provocó fuertes críticas en todo el mundo. Ese será el ensamblaje institucional con que va a entrar en contacto la elite médica chilena.

El hecho de que, además de los médicos chilenos, también otros colegas del resto de los países latinoamericanos y de numerosos países de la Europa ocupada por los nazis (pero antes de 1940 también de países democráticamente organizados) establecieron contacto en Congresos, por ejemplo, con el resto de la medicina alemana, pervertida y amputada por los nazis, no disminuye la gravedad de la responsabilidad y el problema, sino que pluraliza la responsabilidad y la culpa.

En 1935, la serie documental se inicia con una carta del jefe de la Legación de Chile, Luis V. de Porto Seguro, a Karl Panhorst, el secretario general del Instituto Iberoamericano de Berlín, solicitándole ayuda para "obtener una beca de la Universidad de Berlín o en algún hospital clínico para el Dr. Raúl Covarrubias (cirujano, ayudante del profesor Sierra), internista del hospital clínico de Santiago y miembro de la Dirección General de Sanidad, que desea especializarse en ortopedia". A esa solicitud, Panhorst responde que ha cursado una solicitud para Covarrubias ante la Fundación Humboldt en nombre de la Academia Médica GermanoIberoamericana. Este inicio de facto de la academia fue anticipado por un contacto que 
estableció el doctor Hahn con el profesor Dr. Munnich, un médico alemán de Valparaíso a quien Hahn llama "sin duda el médico más preeminente de Chile", y el cual le hizo llegar los formularios y la circular para que los médicos chilenos comenzaran a inscribirse, y en otra carta a Faupel, del mismo día, le comunica que el hijo del cónsul general de Alemania en Valparaíso, Soehring, viene a la clínica Charité a coordinar y organizar las acciones de la academia, asesorando además, a los médicos chilenos que vengan. Se trata de hacer un catálogo, además, de todos los hospitales y centros de investigación a fin de que puedan venir varios cientos de médicos sin costo para los participantes. Estos solo deben pagar su propia estancia.

El profesor Dr. Hardtman escribe al Dr, Hahn, el 18 de agosto de 1935, agradeciendo el envío de revistas médicas, pero insistiendo en que "también le interesa mucho el material de propaganda. Sin duda lo haremos llegar a los círculos importantes”. En su carta se despide con un saludo alemán y Heil Hitler! A partir de aquí se inicia la organización de las visitas de médicos alemanes a Concepción en el contexto de las actividades de la academia. Las actividades de ésta en el año 1935 terminan con una primera conferencia-informe del profesor Benthin ante la primera asamblea de la academia, que contiene los más elevados tonos nacionalistas y en defensa de una propaganda más activa en pro de una rápida expansión de las ideas fascistas.

El primer intercambio acontece, no solo con preferencia entre alemanes, sino también en el más estricto sentido partidista. Así sucede entonces que el viajero siguiente deberá ser “también de Concepción”, a saber el Dr. Hardy Braemer, un chileno-alemán, ex alumno del profesor Westwnhofer (Berlín).

Los primeros que llegaron a Berlín fueron los doctores Luis Bisquertt (25 de octubre de 1935) y Ricardo Olea (21 de noviembre de 1935). El partido (Landesgruppe Chile) solicita, además, el envío de material adicional. Comienza así la intervención directa de la dirección del partido nazi en Chile en la proposición, selección y contacto con los médicos chilenos que viajan al Reich. El 6 de febrero de 1936 llega a Alemania Sótero del Río, quien fue ministro, y las autoridades médicas alemanas reciben instrucción de una especial atención para él, debido a que además de médico es una importante personalidad política del país. 
En 1936 llega a Alemania el médico Emilio Aldunate Phillips con una beca del Servicio de Intercambio Académico Alemán y otra de la Fundación Humboldt. La dirección local del NSDAP (AO) en Chile comunica que el Dr. Aldunate es nacista. Él tiene, de parte del “movimiento nacista de Chile", la misión de estudiar en Alemania el Servicio del Trabajo y el Servicio de Salud y tendría mucho gusto en trabajar como médico en uno de los campos de trabajo. El 22 de septiembre se le comunica a Aldunate Phillips, la resolución de permitirle conocer los campos de trabajo en Alemania. El 3 de octubre de 1936, después de haberse comunicado que el Dr. Aldunate Phillips va a permanecer ocho meses en Alemania para perfeccionar sus estudios de medicina y cirugía en la clínica Charité, se anuncia a la Asociación General de las Agrupaciones Anticomunistas de Alemania, comunicándole que los doctores Julio Terrazas y Emilio Aldunate Phillips piden material sobre la lucha contra el comunismo en Alemania. En la comunicación se dice: “Aldunate es nazi, el Dr. Terrazas es un recomendado de la Embajada chilena y está encargado por el gobierno para que estudie cirugía".

El libro de Víctor Farías "Los nazis en Chile", trae una larga lista de médicos que encontraron trabajo y estudio en Alemania durante los años que precedieron a la ruptura de relaciones entre Chile y Alemania en 1943.

La mayor parte de esos médicos viajaron con el deseo de perfeccionar sus conocimientos en las Universidades y Centros Médicos de Alemania que habían sido muy importantes antes del dominio nazi, pero que continuaban manteniendo una reputación que hacía de ellos un centro de atracción a los médicos que deseaban perfeccionarse. No todos los médicos que llegaron a Alemania eran simpatizantes del régimen nazi, los hubo aquellos que rechazaron esas ideas e incluso ayudaron a médicos judíos alemanes expulsados de las Universidades de ese país a llegar a Chile y aportar un importante impulso al progreso de la medicina chilena.

\section{El escándalo de la circuncisión en el rito judío, del nieto del Presidente Alessandri}

Arturo Alessandri fue presidente de Chile durante dos períodos, de 1920 a 1924 y de 1932 al 1938. De trayectoria liberal, tuvo gran popularidad entre los estudiantes y las clases modestas. 
Su triunfo en 1920 fue una verdadera apoteosis y desde ese momento se le dio el título de León de Tarapacá, en recuerdo de su triunfo en una difícil elección, como senador de la provincia de Tarapacá. Casado con Rosa Ester Rodríguez, tuvieron ocho hijos, todos ellos realizaron exitosas carreras en el ámbito académico y político. Hernán y Mario Alessandri fueron destacados médicos, Arturo tuvo una importante figuración en la Universidad, mientras que Eduardo y Fernando hicieron carrera política en el Congreso, este último llegó incluso a presentarse como candidato a la presidencia. Por último su hijo Jorge Alessandri llegó a la presidencia de la República en el decenio del 60 del siglo XX. Respecto a sus hijas, Ester se casó con un destacado político y empresario y Marta con el talentoso médico pediatra, Arturo Scroggie ${ }^{7}$.

Arturo Scroggie hizo sus estudios principalmente en Alemania, siendo su principal profesor Henrich Finkelstein (importante catedrático de medicina infantil, nació el 31 de Julio de 1865 en Leiptzig, Alemania y falleció en Santiago el 28 de Enero de 1942). Finkelstein fue uno de los pioneros de la medicina pediátrica en Alemania, teniendo numerosos discípulos, tanto alemanes como de países extranjeros, entre otros Chile. El padre de Finkelstein fue el presidente de la comunidad judía alemana en su ciudad, de él heredó el hijo un amor por la naturaleza y el alpinismo, por ello sus primeros estudios universitarios fueron sobre geología y ciencias naturales. Esos estudios los realizó en la Universidad de Leiptzig y Munich. En 1884, a la edad de 23 años, recibió su título de Doctor en Filosofía, luego de lo cual estudió medicina, graduándose en 1892. Desde ese momento comenzó su brillante carrera, ya sea enseñando, investigando o escribiendo numerosos libros y tratados sobre pediatría. Durante sus estudios en Alemania, Scroggie fue nombrado ayudante del Dr. Finkelstein y entre los dos publicaron cuantiosos trabajos sobre la materia de su especialidad.

El título de profesor estaba vedado para los judíos y por lo tanto a Finkelstein se le dio un título de profesor visitante.

Con la subida de Hitler al poder se vio obligado a renunciar a su puesto y estar en peligro de ser enviado a un campo de concentración. El Dr. Scroggie, que ya había regresado a Chile, se preocupó activamente por conseguir a su maestro una visa de entrada a este país, que en ese

\footnotetext{
${ }^{7}$ Extraído de " Memoria Chilena "Publicación Digital
} 
tiempo era muy difícil, pero gracias a sus contactos e influencias, lo logró. Finkelstein llegó a Chile, pero no pudo ejercer como médico debido a que la legislación chilena solo admitía en ese oficio a ciudadanos chilenos, por lo tanto Scroggie le consiguió un puesto de portero en la universidad, pero tanto él como sus discípulos y otros pediatras del país, usaron la experiencia y el conocimiento del profesor judío alemán para mejorar sus investigaciones y servicios a favor de los niños ${ }^{8}$.

En julio de 1936 nació un hijo del Dr. Arturo Scroggie y de Marta Alessandri. Scroggie, que era uno de los más importantes pediatras chilenos en su tiempo, decidió pedir al Mohel $^{9}$, que efectuara la circuncisión de su hijo, nieto del presidente de Chile. Lo hizo por motivos de salud y no de religión. El acto no pasó desapercibido y en el periódico Mundo Judío escribieron lo siguiente:

El día Lunes primero del actual mes (Junio), se llevó a efecto la operación de circuncisión de un hijo del Dr. Arturo Scroggie y Señora. El Dr. Scroggie es yerno del Presidente de la República, don Arturo Alessandri. En tal ocasión actuó el Mohel Levy Katz, quien fue muy felicitado por el padre del niño y por S.E., que se encontraba presente. Al contestar las felicitaciones del Mohel Levy Katz, este informó que esa circuncisión había sido la 4.348 que había efectuado.

La noticia no pasó desapercibida y el diario “Trabajo”, del 10 de Junio de 1936, Número 261, órgano del Partido Nazi Chileno publicó la crónica con el título: "El peligro judío en Chile".

El Presidente de Chile no comentó la noticia, pero su vocero declaró que la circuncisión realizada al nieto no correspondía a un reconocimiento de rito judío, sino que se trataba de una operación quirúrgica para mantener la salud del niño. Por su parte el Dr. Scroggie, entrevistado por la prensa, confirmó esta información y además insinuó que él no apreciaba a los judíos. Al parecer esta declaración fue realizada para evitar la continuidad de la campaña del periódico "Trabajo"10. La historia referida en este artículo demuestra algunas facetas de la

\footnotetext{
8 Los datos personales del Dr. Finkelstein fueron extraídos de Wikepedia. http://en.wikipedia.org/wiki/Heinrich Finkelstein

${ }^{9}$ Mohel es la persona especializada en realizar la circunsición, puede ser un rabino o un médico preparado para la realización de este importante rito judío..

${ }^{10}$ Trabajo (Santiago) - del 10/06/36
} 
vida judía en Chile en los años en que el peligro hitlerista era palpable y tenía como resultado una feroz campaña antisemita.

Entre los problemas que se crearon en Chile con motivo de la inmigración judía al país, fue el “escándalo" de dicha inmigración a Chile durante los años 1938-1940. En enero de 1940, el gobierno chileno prohibió totalmente la inmigración de judíos al país. Pero debemos recalcar que entre los chilenos no judíos, hubo numerosas personas que ayudaron a esos refugiados a llegar al país y a insertarse en el quehacer nacional, de acuerdo a su profesión o capacidad ${ }^{11}$.

\section{EI Profesor Hubert Abrahamson}

Este profesor se especializó entre otras cosas en psicología y que enseñó en la Universidad de Berlín donde conoció y atendió al famoso pianista chileno Claudio Arrau, quien en sus primeras actuaciones musicales tuvo una crisis nerviosa que le hizo abandonar su carrera musical. El Dr. Abrahamson logró curarlo de su problema y transformarse en un íntimo amigo del pianista. Al ser expulsado de su puesto en la Universidad de Berlín como ocurrió con otros profesores judíos, Abrahamson se estableció en París, Claudio Arrau lo convenció para que se instalara en Chile y realizó todas las diligencias necesarias para ese objeto. En declaraciones a la prensa expresó su felicidad en reanudar su actividad personal en Chile ${ }^{12}$.

\section{El caso del Profesor Jorge Nicolai}

Otro profesor judío que había sido además docente de la Universidad de Berlín antes de la subida de los nazis al poder y que tenía una ideología comunista, perseguido como otros profesores, logró llegar a Argentina, de ahí fue expulsado debido a su ideología comunista y llegó a Chile. En Chile fue aceptado como docente de la Universidad de Chile y contó con gran popularidad no sólo entre sus colegas sino que también con los estudiantes, los que le organizaron una serie de conferencias en el Salón de Honor de la Universidad de Chile y lo

\footnotetext{
Trabajo (Santiago) - del 19/06/36 - Nro. 262 con el título “ Dr. Scroggie calumniado por Mundo Judío.

${ }^{11}$ Revista Oriente y Occidente-Investigaciones Históricas-Dr. Moshe Nes-El -Septiembre- Octubre 2011

12 *Mundo Judío“Santiago.26 - 12 - 1935
} 
apoyaron contra la violenta campaña en su contra del Órgano del Partido Nacista de Chile, el diario "Trabajo"

\section{La propaganda en Chile contra la llegada de médicos judíos al país}

La prensa nazista y simpatizante del nazismo, el periódico católico "El diario ilustrado" y otras publicaciones, sacaron artículos en 1933 que llamaron "la invasión de los médicos judíos que llegaban refugiados a Chile", muchos de ellos fueron impedidos de ejercer su profesión en forma oficial, pese al renombre que tenían algunos en el mundo científico.

El nazismo no se conformó con la publicación de esas aseveraciones antisemitas, sino que también usó de médicos de origen alemán y de orientación nazista para tratar de influenciar en la opinión pública chilena.

\section{El caso del profesor Monckeberg}

El citado profesor era catedrático de la Universidad de Chile, principalmente especialista en obstetricia. Tenía una excelente reputación y enseñaba también a los estudiantes judíos que estudiaban esa profesión. A fines de enero de 1936 se realizó un Congreso de Medicina destinado a discutir los problemas del aborto. En ese Congreso el profesor Monckeberg dictó una conferencia atacando el aborto y manifestando que los médicos que lo practican son en general "extranjeros" que con esa actitud limitan la natalidad chilena y aumentan la población racial extraña al pueblo chileno. Para los asistentes en dicha conferencia era claro que el profesor Monckeberg se refería a los judíos y a la inmigración judía a Chile que en ese momento comenzaba a desarrollarse debido a los acontecimientos en Alemania. "El Mercurio" apoyó las aseveraciones del profesor Monckeberg en un artículo publicado el 26 de enero de 1936 con el título "En defensa de la vida y por el honor nuestro".

La intervención del profesor Monckeberg tuvo eco en los órganos de prensa y también en la publicación "Mundo Judío" que editaba la Federación Sionista de Chile.

\footnotetext{
13 "Trabajo"No 15 del 10-8-1933, "Trabajo” No 19 del 14-9-1933
} 
En "Mundo Judío" publicaron fuertes críticas los periodistas judíos, Robert Levy y Salas Abra. También los médicos de origen judío que habían egresado de la Universidad de Chile y que habían sido alumnos de Monckeberg publicaron en "Mundo Judío" una declaración condenando no solo esa intervención del profesor, sino también las continuas declaraciones antisemitas que emitía en sus conferencias ${ }^{14}$.

Otro profesor de la Universidad, el profesor José Garafulic, hijo de inmigrantes eslavos, médico de nota, egresado de la Universidad de Chile habiendo dirigido distintos establecimientos médicos en Magallanes y en el momento de escribir su crítica era director del Manicomio Nacional, Garafulic, que era considerado uno de los mejores profesores de la Universidad, atacó fuertemente al profesor Monckeberg y a sus ideas, tanto por ser anticientíficas como por estar mezcladas con un odio ciego antisemita ${ }^{15}$.

\section{Conclusión}

En los tumultuosos años del poderío nazista entre 1933 y 1943, los médicos chilenos, como todos los habitantes del país se dividieron en aquellos que apoyaban el racismo y el nazismo y los que los condenaban. En un principio el ataque antisemita tuvo gran impulso alentado por los triunfo de Alemania en Europa y la conquista de ese país de gran parte de las naciones europeas. Esa efervescencia antisemita y nazista tuvo mucho eco entre 1939 y 1941. En esos años en que comienza la decadencia de la potencia nazista se organizan mejor las fuerzas democráticas de Chile, se crea el instituto anti-racista de Chile, cuyo primer presidente, Cristóbal Saenz fue también Ministro de Relaciones Exteriores y Colonización, y también se creó la alianza de Intelectuales de Chile, Institución anti-nazi militante. Además comenzó la edición del periódico "Civilización" que polemizaba con los regímenes, nazista, fascista y franquista. Estas ideologías nazistas tenían una abundante cantidad de revistas y periódicos

\footnotetext{
${ }^{14}$ En momento de realizarse la polémica con el profesor Monckeberg, se publicó en "El Mercurio "y en "Mundo judío" una declaración de los médicos judíos chilenos. Según las estadísticas de 1930, los judíos registrados en Chile antes de la gran inmigración era de 3.697 judíos en una población total de 4.207.000. Por lo tanto los médicos chilenos que habían estudiado en la Universidad con el profesor Monckberg eran pocos. En la declaración de los doctores, además de condenar la intervención del doctor Monckberg en la discusión sobre el aborto recalcan la continua actividad anti-semita y racista de dicho profesor. Publicamos los nombres de los doctores que firmaron el manifiesto publicado en Mercurio y Mundo Judío publicado en 1933 con el objeto de registrar la nomina de los médicos egresados de la Universidad en esa epoca : Dr. Mauricio Wonstein, Dr. Jacobo Browfman, Dr. Miguel Waisbluth, Dr. Isaac Horwitzg, Dr. Adolfo Kaplan, Dr.Marcos Charme.

${ }^{15}$ Véase "Mundo Judío y la prensa general" 23 de enero al 31 de enero de 1936.
} 
que diariamente publicaban noticias tanto a favor de Alemania como en contra de los judíos en Chile y en el mundo.

Con el declinar de Alemania y su posterior rendición, las voces nazistas disminuyeron aunque siguen vigentes en pequeña proporción en el momento de escribir estas líneas.

\section{Bibliografía}

Butland, G. (1962). The human geografy of southern Chile. Longmans Green and Co,

Nes El, M. (2012). Las ideas nacionalistas en Chile. Cuadernos Judaicos n ${ }^{\circ}$ 29. Centro de Estudios Judaicos. Universidad de Chile, págs. 104-154.

Nes El, M.(2011) Investigaciones Históricas. Revista Oriente y Occidente. SeptiembreOctubre.

- "Trabajo“" N 15 del 10-8-1933.

- “"Trabajo“" N 19 del 14-9-1933.

- "Trabajo" (Santiago) - del 10-06-1936.

- “Trabajo” (Santiago) - del 19-06-1936 - N²62 con el título “ Dr. Scroggie calumniado por Mundo Judío.

Farías, V. “Los Nazis en Chile” Volumen I y II.pag. 105 a 121.

Labarca, A. (1939). Historia de la educación en Chile. Imprenta Universitaria: Santiago.

Pérez Rosales, V. Recuerdos del pasado. En Memoria Chilena. Publicación Digital. http://www.memoriachilena.cl/602/w3-article-7678.html

"Mundo Judío y la prensa general. Santiago, 23 de enero al 31 de enero de 1936.

Sobre el Dr. Finkelstein, cfr. http://en.wikipedia.org/wiki/Heinrich_Finkelstein. 